\title{
Cuando los enfermos van a la justicia. Denuncias de varones por contagio venéreo y prácticas punitivas en la provincia de Buenos Aires (1936-1954)
}

When the Sick Go to Court: Men's Judicial Complaints for Venereal Transmission and Punitive Practices in Buenos Aires Province (1936-1954)

Quand les malades vont au tribunal : plaintes masculines pour contagion vénérienne et pratiques punitives dans la Province de Buenos Aires (1936-1954)

\section{Carolina Biernat}

\section{OpenEdition}

Journals

Edición electrónica

URL: http://journals.openedition.org/rhj/1295

DOI: $10.4000 /$ rhj. 1295

ISSN: 0719-4153

Editor

ACTO Editores Ltda

Referencia electrónica

Carolina Biernat, «Cuando los enfermos van a la justicia. Denuncias de varones por contagio venéreo y prácticas punitivas en la provincia de Buenos Aires (1936-1954) », Revista Historia y Justicia [En línea], 10 | 2018, Publicado el 02 mayo 2018, consultado el 18 marzo 2020. URL : http:// journals.openedition.org/rhj/1295; DOl : https://doi.org/10.4000/rhj.1295 


\title{
CUANDO LOS ENFERMOS VAN A LA JUSTICIA. DENUNCIAS DE VARONES POR CONTAGIO VENÉREO Y PRÁCTICAS PUNITIVAS EN LA PROVINCIA DE BUENOS AIRES (1936-1954)
}

\author{
Carolina BIERNAT $(*)$
}

Los enfoques clásicos de la historia de la salud conciben a los enfermos como sujetos pasivos intervenidos por las instituciones médicas, poco influyentes en la modelación de las intervenciones públicas sanitarias. Nuestro objetivo es relevar el rol activo de los enfermos venéreos a través de la reconstrucción de los conceptos androcéntricos y las prácticas de acción con las que apelaron a la justicia. Para ello abordaremos uno de los aspectos punitivos de la profilaxis venérea en Argentina a partir de 1936: la penalización por contagiar una dolencia de transmisión sexual. Presentaremos las discusiones de médicos, juristas y funcionarios sobre esta normativa y su aplicación, y, analizaremos las causas judiciales iniciadas por varones contra mujeres por haber sido contagiados de "dolencias secretas".

Palabras Clave: Argentina, siglo XX, enfermedades venéreas, denuncia judicial, cultura androcéntrica

\section{When the Sick Go to Court: Men's Judicial Complaints for Venereal Transmission and Punitive Practices in Buenos Aires Province (1936-1954)}

Traditional approaches in the history of health and illness have usually conceived of the sick as passive subjects, subjected to the intervention of medical institutions or social policies, with little influence in shaping health policies. The aim of this article is to highlight the active role played by men suffering from venereal diseases. It reconstructs the androcentric notions and active practices that they displayed when reaching out to the justice system. Thus, this article studies the punitive dimension of Argentinean prophylaxis policy: the criminalization of the transmission of venereal diseases. The article presents the debates between jurists, doctors, and public officials about this regulation and its application; then, it turns to the analysis of trial records initiated by men against women for having been infected with a "secret ailment".

Keywords: Argentina, XXth century, venereal diseases, judicial complaint, androcentric culture
Quand les malades vont au tribunal : plaintes masculines pour contagion vénérienne et pratiques punitives dans la Province de Buenos Aires (1936-1954)

Les approches traditionnelles de l'histoire de la santé conçoivent les malades comme des sujets passifs, sur lesquels interviennent les institutions médicales. Ils exercent peu d’influence sur le façonnement des interventions sanitaires publiques. L'objet de ce texte est de révéler le rôle actif des malades vénériens par la reconstruction des concepts androcentrés et les actions pratiques menées pour ester en justice. Pour cela, nous aborderons l'un des aspects punitifs de la prophylaxie des maladies sexuellement transmissibles en Argentine à partir de 1936 : la pénalisation de la transmission sexuelle et volontaire d'une maladie vénérienne. Nous présenterons les discussions et débats des médecins, juristes et fonctionnaires sur cette norme et son application. Enfin, nous analyserons les plaintes judiciaires d'hommes contre des femmes pour les avoir contaminés par des "affections secrètes".

Mots clé: Argentine, XXe siècle, maladies vénériennes, plainte judiciaire, culture androcentrée

(*) Doctora en Historia, Universidad Nacional del Centro, Provincia de Buenos Aires. Investigadora adjunta y docente ordinaria, CONICET, Centro de Estudios en Historia, Cultura y Memoria, Universidad Nacional de Quilmes, Argentina. cbiernat@yahoo.com 


\title{
Cuando los enfermos van a la justicia. Denuncias de varones por contagio venéreo y prácticas punitivas en la provincia de Buenos Aires (1936-1954)
}

\author{
Carolina BIERNAT
}

\section{Introducción}

Durante la década de 19301, Argentina, en consonancia con un conjunto de recomendaciones de organismos sanitarios internacionales como, por ejemplo, la Oficina Sanitaria Panamericana o el Comité de Higiene de la Sociedad de las Naciones ${ }^{2}$ y como consecuencia de intensos debates en los círculos médicos, políticos, administrativos y de la sociedad civil, reformuló su agenda pública en torno a la prevención y el tratamiento de las enfermedades de transmisión sexual. Si bien se produjo una suerte de consenso en los postulados básicos, cada actor que formó parte de los debates hizo énfasis en distintos aspectos de la reformulación del programa de profilaxis venérea ${ }^{3}$. Mientras que la academia médica y las reparticiones sanitarias pusieron el acento en la necesidad de un tratamiento

\footnotetext{
${ }^{1}$ Una versión preliminar de este trabajo fue presentado en el I Workshop: "Fuentes judiciales, estudios sociales y género". Universidad Nacional de Quilmes, Agosto 2017.

2 Durante los últimos años de la década de 1920 y los primeros años de la década de 1930, la Oficina Sanitaria Panamericana centró sus recomendaciones de profilaxis venérea en torno a la propaganda informativa y de educación sexual, la extensión de la práctica de exámenes serológicos a sospechosos de infección, la ley de responsabilidad de los padres por la salud de sus hijos, la autopsia de los nacidos muertos y la instalación de clínicas especializadas en las que se atendiera y medicara gratuitamente a los pacientes. Al respecto ver: "VII Conferencia Sanitaria Panamericana", Boletín de la Oficina Sanitaria Panamericana, vol. 6, n 12, 1927, p. 835 y "II Conferencia Panamericana de directores nacionales de sanidad", Boletín de la Oficina Sanitaria Panamericana, vol. 10, $\mathrm{n}^{\circ}$ 6, 1931, p. 702. Respecto del Comité de Higiene de la Sociedad de las Naciones, que propuso similares recomendaciones ver: Barona, Josep Lluis \& Bernabeu-Mestre, Josep, La salud y el Estado. El movimiento sanitario internacional y la salud española (1851-1945), Universidad de Valencia, Valencia, 2008, p. 149-151.

${ }^{3}$ En este artículo utilizamos la palabra venérea como sinónimo de enfermedad de transmisión sexual. Aunque no desconocemos el significado estigmatizante hacia las mujeres, consideradas como responsables de la transmisión de la dolencia en el acto sexual, que históricamente se le ha atribuido, por una razón de economía visual evitamos encomillarla cada vez que aparece en el texto.
} 


\section{Revista Historia y Justicia}

unificado y obligatorio de las afecciones, en la identificación y denuncia de los portadores del mal y en la centralización de la administración sanitaria encargada del problema, agrupaciones de la sociedad civil, ocupadas de los aspectos preventivos, subrayaron la importancia de la propaganda, la educación sexual y la instauración del certificado prenupcial obligatorio. Por su parte, los legisladores, si bien aceptaron esta agenda, debatieron más fuertemente si ella debía estar unida, en una misma ley, con la abolición del sistema reglamentarista de la prostitución ${ }^{4}$.

En la médula de este cambio se encontraban los descubrimientos acerca de que la mayor parte de las dolencias venéreas eran hereditarias, congénitas e intergeneracionales y, en virtud de ello, podían afectar negativamente a la reproducción cuantitativa (mortalidad infantil, descenso del número de nacimientos por abortos y esterilidad) y cualitativa (enfermedades físicas y mentales) de la población. En un contexto de guerras, de crisis capitalista mundial y de re-configuración de los Estados nacionales, los discursos poblacionistas -de profusa circulación en la esfera pública argentina-, asociaron el crecimiento del factor humano con la potencialidad de modernización económica, política y social de los países, en la medida que proveía trabajadores, consumidores, ciudadanos y soldados saludables y compatibles con una supuesta homogeneidad "racial", base de una ciudadanía exenta de conflictos 5 .

Esta premisa reforzó la catalogación de los padecimientos venéreos como enfermedades sociales, ya que se creía que ponían en peligro a la salud de la nación y a su capacidad de desarrollo, y la legitimación de la intervención del Estado en aspectos hasta el momento considerados de orden privado. En consecuencia, el carácter individual y vergonzante de las dolencias de transmisión sexual -entendidas como signo de una conducta sexual condenable que incluía la frecuentación de prostitutas, consideradas como el foco principal de contagio ${ }^{6}$ , dio paso a una interpretación en la que la responsabilidad colectiva asumió un primer plano en los discursos y las prácticas públicas. No obstante ello, como veremos en el segundo apartado, la intención de la política sanitaria no se correspondió con la vivencia de los enfermos que seguían experimentando como intimidante y vergonzoso el diagnóstico y deseaban transferir la culpa de su padecimiento a quien los había contagiado.

Por otro lado, a principios del siglo XX, las enfermedades de transmisión sexual atravesaron un proceso de autonomización en virtud de los descubrimientos bacteriológicos e inmunológicos que contribuyeron a su diferenciación. El caso más paradigmático fue el de

4 Biernat, Carolina, "Médicos, especialistas, políticos y funcionarios en la organización centralizada de la profilaxis de las enfermedades venéreas en la Argentina (1930-1954)", Anuario de Estudios Americanos, vol. 64, nº7, 2007, p. 257-288.

${ }^{5}$ Biernat, Carolina, "Debates poblacionistas en la matriz de la política social argentina de entreguerras", Anuario del Centro de Estudios Históricos "Profesor Carlos Segreti”, vol. 11, n¹1, 2011, p. 189-208.

6 Mujica, María Luisa, "Males vergonzantes" y prostitución reglamentada. Rosario, Argentina (1874-1932)", Asclepio. Revista de Historia de la Medicina y de la Ciencia, vol. 68, n², 2016, p. 35-52. 
la sífilis en torno a la cual, según lo ha propuesto el médico y sociólogo polaco Ludwick Fleck, se consolidó un concepto moderno de la enfermedad en función de los hallazgos científicos respecto de su agente causal (espiroqueta), de su test diagnóstico (prueba de Wassermann) y de la medicación para curarla (salvarsán) 7 . Es justamente en esta tríada que se configuraron una nueva profilaxis y tratamientos de las dolencias de transmisión sexual que fueron crecientemente puestos en práctica por la mayor parte de los sistemas sanitarios de Occidente, entre ellos el argentino. La prueba de laboratorio detectaba el agente causal, distinguía el estadio en el que se encontraba la enfermedad y probaba la curación del paciente una vez administrado el tratamiento. En cambio, la medicación intentó contribuir, con relativo éxito hasta la popularización del uso de la penicilina a mediados del siglo XX, a la desaparición de los síntomas y a la negativización de la bacteria en el enfermo ${ }^{8}$.

En la conjunción entre una concepción de tipo social de la enfermedad y de los descubrimientos científicos que contribuyeron a su diferenciación, la profilaxis centrada exclusivamente en el control de las casas de lenocinio y de las mujeres que trabajaban en ella ${ }^{9}$, fue reemplazada en Argentina por un conjunto de disposiciones reunidas en la ley de profilaxis social ( $\left.\mathrm{n}^{\circ} 12.331\right)$, sancionada en 1936. Ellas atendían a la prevención del contagio, al diagnóstico y al tratamiento de las enfermedades de transmisión sexual de la población en su conjunto ${ }^{10}$.

La historiografía local ha avanzado en el análisis de algunas dimensiones de la profilaxis de las enfermedades venéreas, inaugurada en 1936. Entre ellas podemos mencionar: la discusión de la puesta en práctica del certificado médico prenupcial para los varones ${ }^{11}$; el proceso de organización y centralización de la prevención y el tratamiento de los "males secretos" por parte de la repartición sanitaria nacional12; los discursos en torno a la necesidad de la educación sexual, por un lado, y, por otro, las nociones de masculinidad y feminidad que

\footnotetext{
${ }^{7}$ Fleck, Ludwig, La génesis y el desarrollo de un hecho cientifico, Alianza, Madrid, 1986, p. 60-66.

${ }^{8}$ Un análisis del impacto de estos descubrimientos en el diseño del diagnóstico y tratamiento de las enfermedades de transmisión sexual en la Argentina en Biernat, Carolina \& Simonetto, Patricio, "Producción, distribución y publicidad de medicamentos en la política de profilaxis venérea argentina de los años treinta" en Carvajal, Yuri \& Correa, María José, Historia de los medicamentos. Apropiaciones e invenciones en Cbile, Argentina y Perú, Ocho Libros Editores, Santiago, 2016, p. 158-179.

9 Guy, Donna, El sexo peligroso: la prostitución legal en Buenos Aires, 1895-1955, Sudamericana, Buenos Aires, 1994; Miranda, Marisa, "Sobre las 'asalariadas del amor': prostitución y norma (Argentina y España, fin-du-siècle)", Trabajos y comunicaciones, vol. 42, nº1, 2015, p. 1-13; y Mujica, María Luisa, “ 'Males vergonzantes' y prostitución reglamentada. Rosario, Argentina (1874-1932)", Asclepio. Revista de Historia de la Medicina y de la Ciencia, vol. 68, n², 2016, p. 35-49.

10 "Legislación Sanitaria", Boletín Sanitario del Departamento Nacional de Higiene, vol. 1, n¹, 1937, p. 402-406.

11 Almirón, Valeria \& Biernat, Carolina, "El Certificado Médico Prenupcial como política social", De prácticas y discursos, vol. 4, $\mathrm{n}^{\mathrm{o}}$ 2, 2015, p. 2-26; y Miranda, Marisa, "Matrimonio y procreación en la ortodoxia eugénica argentina", Sociobistórica, vol. 17, nº1, 2005, p. 151-178.

12 Biernat, C., "Médicos, especialistas, políticos y funcionarios", Op. Cit., p. 257-288.
} 


\section{Revista Historia y Justicia}

ISSN 0719-4153 revista.historiayjusticia.org

N¹0 - Santiago de Chile, abril 2018, p. 104-129

desplegaron la corporación médica y los funcionarios de las instituciones estatales ${ }^{13}$; la abolición de la prostitución reglamentada ${ }^{14}$; y las formas en que la política sanitaria se interconectó con la producción y con la publicidad de mercancías que prometieron curar dichas dolencias ${ }^{15}$.

En este artículo, que se enmarca en un proyecto de investigación de mayor envergadura sobre las relaciones sexo-comerciales y las enfermedades de transmisión sexual, me interesa abordar uno de los aspectos punitivos de la profilaxis venérea contenido en la ley n ${ }^{\circ} 12.331$ sancionada en 1936: la penalización por contagiar una dolencia de transmisión sexual. Mi objetivo no se centra en analizar la puesta en práctica de esta normativa ni en sopesar el impacto cuantitativo de su aplicación en la política de profilaxis venérea. Desde otra perspectiva, me interesa estudiar cuál fue el marco jurídico-legal de una disposición de sustrato androcéntrico -que dejaba, además, lugar a una arbitrariedad interpretativa judicial que dificultaba su aplicación- en el que algunos enfermos pudieron hacer escuchar su voz como tales. Para ello, presento en primer término las discusiones de médicos, juristas y funcionarios en torno a esta normativa y su aplicación, para enfocarme, en segunda instancia, en el análisis de causas judiciales iniciadas por varones contra mujeres por haber sido contagiados de una enfermedad de transmisión sexual. Los expedientes judiciales que utilizo en este trabajo fueron seleccionados de un corpus de 65 carpetas consultadas en el Departamento Histórico Judicial de Dolores (DHJS) y en el Departamento Histórico Judicial de Mercedes (DHJC), ambos distritos situados en la provincia de Buenos Aires, Argentina. Estas carpetas abordan causas judiciales por proxenetismo, estupro, abandono del hogar, contagio de enfermedades venéreas, facilitación de la prostitución y corrupción de menores. También considero los registros del Servicio Penitenciario Bonaerense (SPB), que incluyen los expedientes de 269 mujeres que fueron apresadas por la ley $\mathrm{n}^{\circ} 12.331$ y por el artículo 202c del código Penal.

Los enfoques clásicos de la historia de la salud y la enfermedad tendieron a concebir a los enfermos como sujetos pasivos intervenidos por las instituciones médicas o por la política social, poco influyentes en la gestación y la modelación de las intervenciones públicas

\footnotetext{
${ }^{13}$ Milanesio, Natalia, "Redefining Men's Sexuality, Resignifying Male Bodies: The Argentine Law of Anti Venereal Prophylaxis, 1936", Gender \& History, vol. 17, n², 2005, p. 463-491 y Queirolo, Graciela, "Género y sexualidad en tiempos de males venéneos (Buenos Aires, 1920-1940)", Nomadías, vol. 17, n¹, 2013, p. 67-88.

${ }^{14}$ Biernat, Carolina, "Entre el abolicionismo y la reglamentación: prostitución y salud pública en Argentina (19301955)", Cuadernos del Sur, vol. 40, n³, 2013, p. 29-48; Grammático, Karin, "Obreras, prostitutas y mal venéreo. Un Estado en busca de la profilaxis" en Gil Lozano, Fernanda \& Pita, Valeria et al (dirs.), Historia de las mujeres en la Argentina, tomo 2, Siglo XX, Taurus, Buenos Aires, 2000, p. 86-104.

15 Biernat, Carolina \& Simonetto, Patricio, "Provisión pública y oferta privada de medicamentos contra las enfermedades 'venéreas'. Argentina 1930-1945”, Revista de Ciencias de la Salud, vol. 15, no2, 2017, p. 54-78.
} 
sanitarias. A pesar de ello, Armus ${ }^{16}$ ha subrayado que, en casos excepcionales, los enfermos se convirtieron en constructores de demandas o reclamos; y recientemente, Biernat y Simonetto $^{17}$ sugieren que los consumidores de medicamentos adquirieron un papel protagónico en la cura de sus propias dolencias. En ese sentido, este trabajo pone de relieve el rol activo de los enfermos de dolencias de transmisión sexual a través de la reconstrucción de las nociones y las prácticas de acción con las que estos varones apelaron a la justicia. De allí que se rastrean los conceptos androcéntricos con los que los ciudadanos entendieron la idea de "salud" y "justicia", para argumentar la necesidad de acción estatal frente al contagio de enfermedades sexuales. Por otro lado, se propone una nueva lectura de esta argumentación: considerarla como una interpretación de saberes que pueden haber sido extendidos entre los sectores populares (y no permanecer solo asociados a agentes estatales, $\mathrm{O}$ a integrantes de la corporación médica, como ha sido en general).

Desde esta perspectiva, se abordan las narrativas de víctimas, acusados, denunciantes, testigos y funcionarios como aquellas palabras que no serían dichas de no ser por la perturbación de la vida cotidiana. Acto que forzó a hablar a actores que generalmente no dejaron registros escritos sobre procesos naturalizados ${ }^{18}$. Los documentos son analizados con precaución metodológica: se balancean las acciones y los discursos de los actores intervinientes en los juicios - denunciados, denunciantes y testigos- con aquellos emitidos por las agencias públicas, sabiendo que éstas últimas actuaron como mediadoras, y tendieron a sobredimensionar su influencia en la vida social ${ }^{19}$. En suma, me enfoco en las historias de vida, entendiendo que allí se tornan palpables las intersecciones entre individuo-sociedad, tramas institucionales y dinámica social ${ }^{20}$.

\section{La normativa y las discusiones por su aplicación}

La ley n¹2.331 de profilaxis venérea, sancionada en 1936, determinó en su artículo 18 la represión con la pena establecida en el artículo 202 del Código Penal -reclusión o prisión entre 3 y 5 años- a quien, "sabiéndose afectado de una enfermedad venérea transmisible, la contagie a otro". Esta disposición punitiva se encontraba estrechamente vinculada con otras tres que estaban también consignadas en la ley: la obligación del tratamiento para las personas

\footnotetext{
16 Armus, Diego, "Cuando los enfermos hacen huelga. Argentina, 1900-1940", Estudios Sociales, vol. XI, n²0, 2001, p. 32-45.

17 Biernat, Carolina \& Simonetto, Patricio, "Imaginar a los enfermos: campañas privadas y públicas de profilaxis venérea en la Argentina de la primera mitad del siglo XX", Meridional, Revista Cbilena de Estudios Culturales, nº9, 2017, p. 113-143.

${ }^{18}$ Farge, Arlette, La atracción del archivo, Edicions Alfons el Magnanim, Valencia, 1991.

19 Putnam, Laura, The Company They Kept: Migrants and the Politics of Gender in Caribbean Costa Rica, 1870-1960, University of North Carolina Press, Chapel Hill, 2002.

${ }^{20}$ Maynes, Mary \& Pierce, Jennifer \& Laslett, Bárbara, Telling stories: The use of personal narratives in the social sciences and history, Cornell University Press, Ithaca, 2012.
} 


\section{Revista Historia y Justicia}

enfermas en período contagioso (artículo 7); la hospitalización forzosa para todo individuo infeccioso que, agotados todos los medios persuasivos, no se sometiera con regularidad a la cura y para aquellos cuyo tratamiento ambulante pudiera constituir un peligro social (artículo 9); y, por último, la denuncia del foco de contagio por parte de los médicos (artículo 10) ${ }^{21}$. Así, una persona podía ser denunciada a la justicia por haber contagiado a otra y, al margen de la pena por ese delito de salud pública, estaba obligada a someterse a un tratamiento médico para su cura y, eventualmente, a ser hospitalizada forzosamente. De todos modos, cabe aclarar que, a partir del sustrato androcéntrico que asimilaba a las prostitutas con el foco de contagio -y que estaba extendido en un amplio arco de actores de la sociedad civil y de los campos médico, policial y judicial-, tanto los varones como las mujeres "decentes" fueron excluidos de la posibilidad de ser denunciados.

La discusión entre los juristas, a propósito de las disposiciones del artículo 18 de la ley de profilaxis social, remitía a viejos debates en el campo del derecho, relativos a los artículos 202 y 203 del Código Penal argentino y su aplicación en los casos de denuncia por contagio venéreo. El prestigioso médico legista y profesor titular de la Universidad de Buenos Aires, Nerio Rojas, sostenía en 1932 que este delito no había sido considerado durante la redacción del Código, ni luego, en sus sucesivas modificaciones; pero que, igualmente, era importante aplicar esos dos artículos a tales casos "dada la importancia social del problema y la tendencia actual de las leyes penales y sanitarias en muchas partes" 22 . Por su parte, el presidente interino de la Corte Suprema de Justicia de la provincia de Tucumán, a propósito de un juicio de contagio por contacto venéreo en el que el fiscal había basado su acusación en la figura de lesiones graves (artículo 90) y el juez lo había calificado como contrario a la salud pública, compartía la posición de Rojas en función de considerar a este delito como contrario a la seguridad pública y a la salud general ${ }^{23}$. En suma, para los altos magistrados judiciales no se trataba de un delito de orden individual, sino que afectaba al colectivo social y, con ello, al desarrollo de la nación.

Otro punto de interpretación jurídica giró en torno a las diferencias en la responsabilidad del acusado según se tratara de propagación dolosa o culposa. Para el primer caso se aplicaría el artículo 202 que penaba con reclusión o prisión entre 3 y 15 años a quien propagase una enfermedad peligrosa y contagiosa y, para el segundo, el artículo 203 que atenuaba ese castigo para el caso en que el contagio de la dolencia fuese producto de imprudencia, negligencia o impericia. La determinación de una u otra calificación del aspecto subjetivo del tipo penal (doloso o culposo) contenido en cada uno de los artículos del Código solía oponer, también, a fiscales y a jueces de distinto orden que intervenían en un mismo juicio. Así por ejemplo,

21 Anales de la Legislación Argentina, 1920-1940, La Ley, Buenos Aires, 1953, p. 706-707.

${ }^{22}$ Rojas, Nerio, "Delito de contagio venéreo. Dolo Eventual”, Archivos de Medicina Legal, vol. IV, nº4, 1934, p. 172.

${ }^{23}$ Rojas, N., "Delito de contagio venéreo. Dolo Eventual”, Op. Cit., p. 165. 


\section{Revista Historia y Justicia}

un sonado caso que llegó a la Corte Suprema de Tucumán en el año 1932, en el que el acusado, consciente de padecer blenorragia, contagió a su amante, una mujer casada. En primera instancia fue acusado por delito culposo pero, finalmente, la Corte lo condenó, teniendo en cuenta el artículo 202 del Código Penal, por dolo eventual a cuatro años de cárcel. Según el juez de la máxima instancia de apelación provincial, no podía rebajarse la condena "dada la naturaleza del delito y la extensión del daño". En efecto, para el magistrado "lo que revela la mayor peligrosidad del reo y su falta de altruismo y sentido moral, es el no haber tenido reparos en dirigir su acción dañina contra una mujer casada a la que ocultó su enfermedad". Además, para el juez, el acusado había "mancillado un hogar, poniendo en peligro, no sólo la salud física y moral de sus componentes, sino también, en potencia, el porvenir de la raza, por las consecuencias hereditarias que trae el contagio"24.

Detrás de esta interpretación -que colocaba a la moral y al altruismo como valores que trasuntaban la decisión del fallo de no conceder una rebaja de la condena-, se encontraba, por un lado, una concepción androcéntrica de la justicia, subrayando que se trataba de un delito, en última instancia, contra la familia y su estructura patriarcal, simbolizada por el marido. Por otro lado, imbuido de premisas eugenistas -imperantes en la época no sólo en el discurso médico argentino sino también en el judicial-, el fallo subrayaba la amenaza que el delito imponía al futuro de la "raza". En efecto, esta corriente de pensamiento partía de la premisa de que todos los caracteres de los seres humanos eran hereditarios, tanto las capacidades y talentos como la propensión a la enfermedad, y se proponía lograr el mejoramiento de la "raza" blanca a través de la reproducción de determinados individuos o grupos humanos calificados como "mejores", inhibiendo la multiplicación de otros grupos o individuos considerados "inferiores", "indeseables" o enfermos. Bajo este supuesto, las dolencias venéreas eran consideradas como una amenaza para la salud de la población y para su acervo hereditario por su transmisión intergeneracional ${ }^{25}$.

El artículo 18 de la ley $n^{\circ} 12.331$, si bien por un lado puso fin al carácter inespecífico que el delito de contagio venéreo poseía en el Código Penal, por otro abrió un nuevo problema de interpretación jurídica en tanto se centró en la figura de dolo que la contravención contenía. Es decir, que para que existiera el delito, debía de haber mediado voluntad deliberada de cometerlo a sabiendas de su ilicitud. Esta exigencia del elemento intencional en la transmisión de la dolencia generaba la crítica por parte de los magistrados: en realidad, la mayor parte de las denuncias no prosperaron en la justicia y, en los pocos casos en que llegaron a juicio, la mayoría de las mujeres imputadas fue absuelta ${ }^{26}$. No obstante, esta lectura extrema por parte

\footnotetext{
${ }^{24}$ Rojas, N., "Delito de contagio venéreo. Dolo Eventual", Op. Cit., p. 169.

${ }^{25}$ Biernat, Carolina, "La eugenesia como matriz ideológica de la política sanitaria (1900-1955)" en Biernat, Carolina \& Cerdá, Juan Manuel \& Ramacciotti, Karina, La salud pública y la enfermería en la Argentina, Editorial de la Universidad Nacional de Quilmes, Bernal, 2015, p. 169-204.

${ }^{26}$ Carnelli, Luciano, Anales de Legislación Argentina 1920-1940, La Ley, Buenos Aires, 1953, p. 741-744.
} 


\section{Revista Historia y Justicia}

del mundo judicial puede ser matizada con el análisis de los registros de quienes efectivamente sí cumplieron con su condena por delito de contagio venéreo. Tomando como ejemplo la unidad penitenciaria y cárcel de mujeres de Olmos de la provincia de Buenos Aires, entre los años 1936 y 1968, solamente 29 mujeres fueron recluidas por este delito ${ }^{27}$.

Si bien la mayoría de las condenadas permaneció en presidio por escaso tiempo (una semana), presumiblemente hasta que mermara su posibilidad de transmitir la dolencia como consecuencia de un tratamiento obligatorio, hubo encarcelamientos que duraron un lapso más prolongado: entre algunos meses a tres años ${ }^{28}$. Esto se conecta con otra discusión vigente en el mundo judicial, relacionada con el artículo 18, que reprimía tanto los casos de contagio doloso como culposo. En consecuencia, si se consideraba que los alcanzaba a ambos, algunos reconocidos juristas y catedráticos de Derecho, como Laureano Landaburu (h) y Enrique Aftalión, reconocían que la pena para los casos culposos era excesiva y que debía permitirse que el juez modificase la pena ${ }^{29}$.

Por otro lado, las desavenencias entre fiscales y jueces por distintas interpretaciones de la normativa, lejos de desaparecer con la ley de profilaxis venérea, subsistieron. Por ejemplo, en 1949, el fiscal pidió 3 años y 6 meses de pena María Zulema, pero el juez de primera instancia la absolvió; finalmente, el juez de segunda instancia la condenó a 3 años de cárcel ${ }^{30}$. En estos debates, los agentes judiciales actualizaron en su decir y hacer interpretaciones de una normativa ambigua. Pero, por otro lado, las desavenencias mostraban la co-existencia de distintas moralidades, cristalizadas en estos fallos, y que estaban conectadas con el tipo de "orden" que buscaban fundar: castigando a la mujer (punitivo) o simplemente curándola (internación forzosa).

Los profesionales de la medicina especializados en dolencias de transmisión sexual, como los venerólogos y los dermatosifilógrafos -muchos de los cuáles se desempeñaban como médicos de hospitales públicos o consultorios venerológicos o funcionarios de las reparticiones sanitarias-, fueron especialmente críticos con las disposiciones del artículo 18 de la ley $\mathrm{n}^{\circ}$ 12.331. Muchos de de ellos participaron en la elaboración de sendos proyectos que promovieron las discusiones parlamentarias; instalaron el tema de la profilaxis venérea en la agenda pública; y presionaron desde sus instituciones de pertenencia (universidades, asociaciones médicas, partidos políticos, instituciones civiles y filantrópicas) para que obtuviera consenso en el congreso. No obstante, estos médicos rápidamente se vieron decepcionados por el texto final de la ley. En efecto, la normativa fue producto tanto de un

\footnotetext{
27 Archivo del Servicio Penitenciario de la Provincia de Buenos Aires, Cárcel de Olmos, 1936-1968.

${ }^{28}$ Archivo del Servicio Penitenciario de la Provincia de Buenos Aires, Cárcel de Olmos, 1936-1968.

${ }^{29}$ Landaburu (h), Leónidas \& Aftalión, Eduardo, "Aspectos civiles, penales y administrativos de la ley 12.331 de profilaxis antivenérea", Revista Argentina de Dermatosifilología, vol 12, n4, 1942, p. 767.

30 Archivo del Servicio Penitenciario de la Provincia de Buenos Aires, Cárcel de Olmos, 1936-1968, año 1949.
} 


\section{Revista Historia y Justicia}

ISSN 0719-4153 revista.historiayjusticia.org

N¹0 - Santiago de Chile, abril 2018, p. 104-129

sinnúmero de acuerdos establecidos entre varios grupos de interés como de presiones provenientes de organizaciones políticas y de la opinión pública internacional. A la organización de la profilaxis y del tratamiento de las enfermedades de transmisión sexual se sumó la decisión de dejar sin efecto el sistema reglamentarista de la prostitución, que permitía el funcionamiento de burdeles siempre y cuando, por un lado, pagaran una tasa a los municipios y, por otro, sus trabajadoras se sometieran a periódicos exámenes médicos ${ }^{31}$.

Entre las objeciones que los círculos médicos hicieron al artículo 18 de la ley, se subrayó su inocuidad, ya que requería que el acusado confesase que se había sido afectado por el mal venéreo en el momento en que éste era contagioso. Según Eduardo Fidanza, profesor de Clínica Dermatosifilográfica de la Facultad de Medicina de Rosario, "esta gran puerta abierta que la ley le ofrece al delincuente, es la causa por la que vemos con frecuencia los casos en los que un mismo sujeto contamina a varias personas, quedando impune su delito". De allí que proponía dos medidas. Por un lado, que se volviera a considerar el aspecto subjetivo del tipo penal doloso contenido en el artículo 202 del Código Penal, y que "en los casos de verdadera excepción que tuvieran que ser contemplados, nadie mejor que la justicia lograría establecer las circunstancias que podrían atenuar la responsabilidad penal, sin eximirlo de la responsabilidad civil". Por otro lado, recomendaba "educar a los jóvenes para que sepan que el que transmite una enfermedad venérea es pasible de castigo"32.

Por su parte, una comisión del Círculo Médico de Córdoba subrayaba lo riguroso de la penalidad impuesta, ya que no distinguía entre el contagio intersexual y aquél que se producía por otras vías como la lactancia, o la transmisión de "determinados gremios (como el servicio doméstico) que en el desempeño de sus funciones facilita la difusión de las mismas por su diario contacto con el ambiente familiar, en forma tan inestable" 33 . Aun si estos especialistas diferenciaban el contagio intersexual de aquél producido indirectamente -probablemente para buscar atenuantes a la pena-, hacían alarde, a su vez, de una interpretación generizada y clasista del contagio, en la medida que consideraban a las mujeres trabajadoras como portadoras de dolencias venéreas y posibles agentes de contagio. En última instancia, lo que estaba en peligro para estos galenos era, por un lado, la reproducción saludable de la población -en la medida que las nuevas generaciones podían estar amenazadas por la transmisión de la enfermedad a través de la lactancia-, y, por otro, la familia, especialmente la de clase media, que podía contratar a personal doméstico en su casa.

\footnotetext{
31 Biernat, C., "Médicos, especialistas, políticos y funcionarios", Op. Cit.

32 Fidanza, Eduardo, "Para que la ley de profilaxis de las enfermedades venéreas n`12.331 y su reglamentación resulten benéficas, se hace indispensable su modificación”, Revista Argentina de Dermatosifilología, vol. XII, n 4, 1938, p. 614.

33 Tey, Aftalión \& Garzón, Roberto \& Brandan, Gerardo, "Informe presentado por la subcomisión del Círculo Médico de Córdoba (a propósito de la ley $\mathrm{n}^{\circ} 12.331$ de profilaxis de las enfermedades venéreas y su reglamentación)", Revista Argentina de Dermatosifilología, vol. XII, nº4, 1938, p. 178.
} 


\section{Revista Historia y Justicia}

Por último, las críticas también se centraban en la dificultad de determinar, en la práctica, la culpabilidad de las personas llevadas a la justicia como acusadas de haber sido agentes de contagio venéreo por contacto intersexual. Según los miembros de la comisión del Círculo Médico de Córdoba, este impedimento se constataba en "los informes llegados hasta nosotros alrededor de un caso de esta naturaleza en un matrimonio en el que la presunta inculpada aparecía indemne de la afección venérea que se le imputaba" 34 . Como veremos en el apartado siguiente, las acusadas solían ser mujeres, en función de una concepción androcéntrica de la propagación de la enfermedad, y si no podía probarse que padecían dolencia alguna, no se seguía con la investigación del foco de contagio.

En suma, las divergencias entre los discursos médicos, los debates jurídicos y lo que los jueces efectivamente decidían, nos muestra la distancia entre sus campos profesionales ocasionalmente cruzados, por ejemplo, en las colaboraciones en revistas especializadas, o en los pedidos de peritaje médico en algunos casos judiciales- y las disputas por las atribuciones sobre los problemas de orden social a resolver.

Para los médicos, desde un punto de vista más práctico y basal, lejos de poner el acento en la denuncia judicial por contagio venéreo, lo que debía hacerse era arbitrar medios para efectivizar la vigilancia de los posibles focos de contagio y su tratamiento obligatorio. Para cumplir con este objetivo se propuso la organización de un cuerpo de Policía Sanitaria, encargado de vigilar a todas las personas que, por su profesión o modo de vida, pudieran constituir un "peligro social" en caso de estar afectadas de una enfermedad venérea. Entre los primeros se contaban bailarinas, nodrizas, servicio doméstico, mozos; en el segundo grupo solo estaban las prostitutas. En una clara asimilación entre enfermo y mujer que ejerce la prostitución, los especialistas insistían en la necesidad de proteger la salud pública y, para ello, hacer cumplir los artículos de la ley que contemplaban, por un lado, la denuncia a las autoridades nacionales, por parte de los médicos, de la fuente de contagio, y por otro, la obligación de tratamiento o, en caso extremo, la hospitalización voluntaria o forzosa ${ }^{35}$.

Respecto de la puesta en práctica de esta normativa, para Pedro Baliña -titular de la Cátedra de Clínica de Dermatosifilográfica de la Facultad de Ciencias Médicas de la Universidad de Buenos Aires, y gran referente y consultor de la profilaxis venérea-, como la reglamentación de la ley preveía la colaboración de las autoridades policiales o municipales con el Departamento Nacional de Higiene, en el caso de las ciudades, el enfermo o el médico señalarían a las autoridades sanitarias el nombre de la persona sindicada como trasmisora de males venéreos. Acto seguido, el servicio social o médico tratarían de probarlo y, en caso de persuadir a la persona inculpada, intentarían que se atendiera de la debida forma hasta su cura. Para las pequeñas localidades, la autoridad sanitaria era el médico de policía; en caso de

34 Tey, A., Garzón, R. \& Brandan, G., “Informe presentado por la subcomisión”, Op. Cit., p. 178.

35 Landaburu (h), L. \& Aftalión, E., “Aspectos civiles, penales y administrativos de la ley n¹2.331”, Op. Cit, p. 771. 


\section{Revista Historia y Justicia}

ISSN 0719-4153 revista.historiayjusticia.org

N¹0 - Santiago de Chile, abril 2018, p. 104-129

no poder ocuparse personalmente, porque los tratamientos eran engorrosos y largos, podría pedir a la partera diplomada que lo asistiera en las curaciones, además de cumplir con funciones de visitadora social ${ }^{36}$.

El decreto reglamentario de la ley n¹2.331 de septiembre de 1946 pareció atender a esta demanda de los especialistas, y consagró una idea mucho más punitiva de la profilaxis venérea. En primer lugar, estableció que todas las mujeres involucradas en el sexo comercializado, en forma dependiente o independiente, serían por definición fuentes de contagio. Eso significaba que los funcionarios municipales y de la policía podían insistir en la supervisión médica de las prostitutas. Además, declaró que la sífilis, la blenorragia, el chancro blando y el linfo-granuloma venéreo serían tratados con el mismo criterio sanitario que cualquier otra afección infectocontagiosa; también, que los pacientes serían sometidos a las medidas generales que se adoptaban con todas las enfermedades transmisibles de acuerdo a la ley $\mathrm{n}^{\circ} 12.317$ del año 1936, que obligaba a declarar y denunciar su padecimiento. Los instrumentos previstos para luchar contra los males venéreos eran: la educación sanitaria, destacando las ventajas de la profilaxis individual; la denuncia obligatoria y confidencial de los enfermos por parte de los médicos, so pena del pago de una multa y de la suspensión de su ejercicio profesional; la investigación de la fuente de contagio (en especial las prostitutas), por parte del médico o del servicio de policía antivenérea; el tratamiento obligatorio de los enfermos; la creación de un Instituto de Higiene Social para la internación de pacientes; penas específicas para todos aquellos que ignoraran la ley, incluidos los médicos; y, por último, la fundación de nuevas dependencias para reunir estadísticas, para controlar el cumplimiento de la ley (policía sanitaria) y para formar al personal técnico especializado (investigadores sociales y venerólogos) ${ }^{37}$.

Así, con respecto a la denuncia del foco o fuente de enfermedad, el decreto ungía a la policía, a través de su servicio antivenéreo, de facultades que le habían sido retiradas por la ley de 1936 -como el control sanitario de las mujeres que ejercían la prostitución-, y de nuevas atribuciones, como la investigación del foco de contagio. No obstante estas nuevas disposiciones, en la práctica, la denuncia obligatoria de los enfermos venéreos y la investigación del foco de contagio fueron muchas veces entorpecidas por la misma policía. Los médicos de un consultorio venerológico de la ciudad de Buenos Aires hacían pública su crítica a las dificultades que habían sufrido dos enfermos de blenorragia cuando se presentaron en la comisaría para hacer la denuncia de su padecimiento y del foco de contagio. Para los galenos, el tiempo demandado por el trámite policial (varios días) y por la revisión médica, perjudicaba a los afectados "en su moral, en sus sentimientos y en su

\footnotetext{
36 Baliña, Pedro, "Libreta de salud obligatoria y lucha antivenérea", Revista Argentina de Dermatosifilología, vol. 21, 1937, p. 611-622.

37 "Reglamentó el P. E. la ley de Profilaxis Social", Revista de la Asociación Argentina de Venerología y Profilaxis Social, vol. X, nº18, 1946, p. 47-56.
} 
economía" (pérdida de días de trabajo) y "tratándose de gente de escasos recursos, el conocimiento de tales molestias puede inducir a los demás a ocultar el origen de su afección y a dar nombres y domicilios supuestos con el fin de eludir inconvenientes"38.

Aun así, es en este contexto, creemos, que se incrementó la judicialización de denuncias por contagio venéreo, que tenían como instancia inicial un sumario policial. Así por ejemplo, en los registros de la Penitenciaría de Olmos, provincia de Buenos Aires, se constatan ingresos de mujeres por el delito de contagio venéreo recién a partir del año 194739 . Se trataba en su totalidad de mujeres que intercambiaban sexo por dinero; lejos de interpretar una profundización del rol de agente sanitario de la policía, podríamos sospechar la presencia de ajustes de cuentas entre prostitutas y miembros de las fuerzas de seguridad, relacionados con el libre ejercicio de la venta de sexo.

El objetivo de la segunda parte del artículo es tratar de comprender, a través del análisis de tres casos judiciales en la provincia de Buenos Aires ocurridos entre 1946 y 1954, cómo los enfermos, a pesar del reforzamiento punitivo de la ley, se apropiaron de los recursos que ésta les proveía para asignarle un sentido y una lógica distinta a sus enfermedades, y dirimir otras batallas.

\section{Los enfermos como actores principales del conflicto}

\section{1 ¿Quiénes denuncian, a quién y por qué?}

Pedro, un pescador de 19 años, se presentó en 1946 ante la comisaría de Necochea -una ciudad media portuaria de la provincia de Buenos Aires que contaba con 17.700 habitantes para la época-, para exigir que se atrapara a dos mujeres con las que había mantenido relaciones sexuales en las semanas previas. Aunque no estaba seguro si se trataba de Carolina o de Catalina, Pedro estaba convencido de que una de las dos le había contagiado blenorragia. Se trataba de dos mujeres jóvenes, que apenas llegaban a la veintena de años, que no tenían una ocupación laboral estable y que vivían en pareja. Una de ellas, Catalina, había tenido un noviazgo años atrás con el muchacho. Según lo testificó Pedro, lo que lo llevó a denunciarlas fue una profusa vergüenza por "dañarle el miembro". No obstante ello, es muy probable que el médico que lo atendió lo haya instado a denunciar; también es posible que sus celos, porque Catalina había conformado una pareja, le hayan jugado una mala pasada ${ }^{40}$.

\footnotetext{
38 Rebaudi, Leónidas \& Paniza, Ignacio, "Comentario sobre la denuncia obligatoria de los enfermos venéreos", Revista de la Asociación Argentina de Venerología y Profilaxis Social, vol. X, n¹8, 1946, p. 109-111.

39 Archivo del Servicio Penitenciario de la provincia de Buenos Aires, Cárcel de Olmos, 1936-1968.

${ }^{40}$ Departamento Histórico Judicial Sur de la Provincia de Buenos Aires (DHJS), Causas Penales (CP), Carpeta (C) 596, Folio (F) 178, Año 1946.
} 


\section{Revista Historia y Justicia}

ISSN 0719-4153 revista.historiayjusticia.org

N¹0 - Santiago de Chile, abril 2018, p. 104-129

En noviembre del año 1952, el jefe de sanidad de la base naval de Mar del Plata importante ciudad portuaria y turística de la provincia de Buenos Aires-, realizó una denuncia policial de un foco infeccioso por epidemia de blenorragia entre los marineros de su base. Según sus propias investigaciones, las responsables del contagio eran las hermanas Adelina y María Pérez, que alegaron ejercer ocasionalmente la prostitución porque se encontraban desocupadas. Iniciado el proceso de instrucción, el comandante de la base informó que provocaba una pérdida para la marina en tanto los marinos debían "permanecer sin servicio durante 15 días". Dos de los tres damnificados, a pesar de haber sido obligados a presentarse a declarar como víctimas, aseguraron no haber mantenido relaciones sexuales con las hermanas sino con otras mujeres que, aparentemente, no ejercían la prostitución. A pesar de ello, y de que las mujeres declararon no haber tenido sexo con ningún uniformado, Adelina y María fueron procesadas ${ }^{41}$.

En julio de 1954 en San Antonio de Areco -pueblo rural de la provincia de Buenos Aires de unos 12.500 habitantes para la época-, un grupo de jóvenes, algunos menores de edad, responsabilizaron a Luisa y a Josefa de haberlos contagiado de sífilis. La denuncia fue iniciada por el comisario de la policía local como consecuencia de una notificación reservada y confidencial, probablemente emitida por el médico del pueblo que había atendido a alguno de los jóvenes y que, además, ejercía como médico de la policía. Luisa, una mujer de mediana edad que vivía en concubinato con un hombre, negó ejercer la prostitución; la "gorda" Josefa, aceptó que tenía sexo por dinero y que lo hacía porque no contaba con otra ocupación laboral. Ambas mujeres fueron procesadas ${ }^{42}$.

En los tres casos, quienes iniciaron la denuncia fueron varones. Desde una concepción androcéntrica de la salud -disponible en la época e impuesta por académicos, hombres públicos, médicos, juristas, funcionarios sanitarios y, como hemos indicado en el apartado anterior, ratificada por el decreto reglamentario de la ley n ${ }^{\circ} 12.331$ del año 1946-, la mujer, fundamentalmente la prostituta o aquella que poseía una moral dudosa y no califica como "decente", era siempre la portadora del mal. El varón, por su parte, tenía la responsabilidad de cuidar su propia salud y la de su progenie, para garantizar la reproducción cualitativa de la población, y el contagio de una enfermedad de origen sexual parecía ser siempre una contingencia. No obstante, algunos médicos denunciaron a partir de su experiencia, en sus consultorios la "tragedia social y familiar" que constituían los maridos, porque ellos, sabiéndose portadores de un mal venéreo, contagiaban a sus esposas y al núcleo familiar más cercano ${ }^{43}$.

${ }^{41}$ DHJS, CP, C733, F9, 1952.

${ }_{42}$ DHJC, CP, C 519, Legajo (L) 1470, 1954.

43 Ambrosino, Nicolás \& Berenguer, Alfredo, "Contagio sifilítico familiar. Responsabilidad y previsión", Revista de la Asociación Argentina de Venerología y Profilaxis Social, vol. 1, n², 1937, p. 145-150. 


\section{Revista Historia y Justicia}

Esta observación de los galenos podría indicar que los varones, lejos de ser un objeto del "control" y de ser construidos "por los discursos dominantes", tenían agencia propia y, en su decir (entendido como acto) y hacer (denunciar), proponían una interpretación particular de lo masculino, en la que sentían posiblemente alguna falta a su honor, generada por el contagio. Si la mujer, fijada socialmente a las tareas de cuidado, faltaba a este deber cuando no tomaba los recaudos suficientes durante el acto sexual, se convertía en impura y deshonesta, y debía ser denunciada.

En ese sentido, los tres casos parecerían mostrar, a priori, una capacidad de agencia limitada de los enfermos que denuncian. Detrás de ellos se encontraban los médicos que los atendieron, sea en el consultorio privado, sea en la base naval, y que los instaron a hacer la denuncia o la hicieron ellos mismos. De todos modos, existen motivos que trascienden esta directiva de los galenos: la vergüenza por sentir "algo anormal en el miembro", el saberse traicionados por una mujer que no los "cuidó" durante y después del acto sexual, el temor a la represalia parental por ser menor de edad o, simplemente, los celos porque una antigua novia había formado pareja con otro hombre. Katie Barclay indicó que los varones irlandeses de las clases populares aprovecharon los testimonios judiciales para presentar y defender su interpretación de la masculinidad ${ }^{44}$. Es posible pensar, entonces, que los varones que denunciaron a mujeres por contagio venéreo utilizaran el estrado judicial como un escenario donde exaltar su virilidad, y poner en evidencia la traición de la mujer a su rol social de cuidadora. Por supuesto que sus narraciones los presentaban como la "víctima ideal". Es decir, subyacía implícitamente una negociación o una complicidad con los representantes del sistema judicial, todos ellos también varones en la época, para que actuaran ajustando los enunciados de los denunciantes al delito.

Por último, si bien el propósito de la ley era determinar el foco de contagio y disponer su cura, la práctica judicial no siempre perseguía el mismo objetivo. Así por ejemplo, en el caso de la denuncia hecha en Mar del Plata, después de descartar la enfermedad de las acusadas, no se abrió otra investigación para continuar con la búsqueda de la fuente de contagio. Además, los varones que, como Gualberto, voluntario marinero de la base, ya había padecido anteriormente blenorragia en dos oportunidades, no se volvieron sospechosos como posibles propagadores de la enfermedad ni se inició una causa contra ellos por ese motivo. Por otro lado, los varones involucrados en la causa de San Antonio de Areco, por ser los concubinos de las mujeres denunciadas, no fueron sometidos a una revisión médica, a pesar de haber declarado que mantenían relaciones sexuales con las mujeres. De este modo, la visión androcéntrica de la salud que los actores policiales y judiciales ostentaban, obturaba la posibilidad de que ellos se convirtieran en agentes de profilaxis de dolencias de transmisión

44 Barclay, Katie, 'Singing, Performance, and Lower-Class Masculinity in the Dublin Magistrates'Court, 18201850", Journal of Social History, vol. 47, n³, 2014, p. 746-768. 
sexual y que se buscara efectivamente al causante del contagio; más bien orientaba sus prácticas punitivas, fundamentalmente, hacia las mujeres que intercambian su sexo por dinero. En este sentido, es muy probable que tanto las autoridades policiales, en cuya sede se iniciaba la denuncia, como las judiciales, estuvieran más preocupadas por penalizar a determinadas mujeres que ejercían la prostitución individualmente -práctica que no se encontraba en absoluto prohibida por la ley-, que en resguardar la salud de la nación, amenazada por las enfermedades venéreas. Contrariamente, los médicos, sea los que advertían en sus consultorios a los enfermos del padecimiento del mal y de la necesidad de denunciar al foco de contagio, sea los peritos que intervenían en las causas, parecían estar mucho más preocupados por la posibilidad de profilaxis social que contenía la denuncia.

Lamentablemente, las fuentes judiciales no nos permiten vislumbrar cuáles eran las razones para, por un lado, hacer prosperar las denuncias hacia ciertas mujeres que intercambiaban sexo por dinero y, por otro, no extender las investigaciones hacia otras, que podían constituir el verdadero foco de contagio. Es muy probable que en el seno de estas decisiones se encontraran arreglos frustrados, entre autoridades del orden y mujeres que deseaban trabajar en determinado territorio, bajo auspicio y protección policial.

\subsection{Intervenciones de los médicos}

En los procesos por denuncia de contagio venéreo, los médicos fueron colocados en un lugar central por la ley $\mathrm{n}^{\circ} 12.331$ y su decreto reglamentario de 1946. Por un lado, eran los encargados de diagnosticar a los enfermos, indicarles un tratamiento y sugerirles la delación del foco de contagio ante las autoridades policiales. Por otro lado, intervenían como peritos en las causas judiciales, a fin de determinar tanto la existencia del foco como las formas de contagio ${ }^{45}$. Esta duplicidad de funciones situó a los galenos en posiciones ambiguas y permitió, en algunos casos, el uso de esta situación, por parte de los involucrados en las causas judiciales, como denunciantes o denunciados.

En las ciudades de tamaño medio que analizamos en este trabajo, algunas veces un solo médico cumplía ambas funciones. Tal el caso de San Antonio de Areco, donde el doctor Juan Durán atendía en su consultorio a algunos de los denunciantes y, a su vez, oficiaba de perito policial. Esta superposición de funciones no sólo atentaba contra la discreción que buscaban, en virtud del carácter "vergonzante" del mal venéreo; muchos de los enfermos acudían a un consultorio privado - en lugar de dirigirse al hospital público- para no exponerse públicamente ${ }^{46}$ y también, para acordar con los galenos el secreto médico para su enfermedad.

45 Riva, Betina, El perito médico en los delitos sexuales, Tesis Doctoral, Facultad de Humanidades y Ciencias de la Educación, Universidad de La Plata, Argentina, 2011.

46 Biernat, C., "Médicos, especialistas, políticos y funcionarios", Op. Cit, p. 270. 


\section{Revista Historia y Justicia}

En ciudades un poco más grandes, como Necochea, el número mayor de médicos disponibles daba lugar a la posibilidad de que las denunciadas apelaran a alguno de ellos, con la condición de que estuviese dispuesto a no delatar el foco de contagio. Tal es el caso del médico que atendió a Catalina, en Necochea, quien, consultado por la policía, aseveró que atendió a la mujer, que ella poseía sífilis desde hacía unos meses atrás, que la enfermedad podía ser contagiada por contacto genital y que le suministró un tratamiento de bismutales y arsenicales que, no obstante, no llegó a término. Por su parte, Carolina utilizó la estrategia de viajar hasta Mar del Plata y consultar con un médico quien, tras hacerle pruebas de orina y de sangre, en un laboratorio, le informó que estaba enferma y le aplicó inyecciones día por medio en su consultorio ${ }^{47}$.

Resulta interesante el contraste entre la posición de estos galenos particulares -cuyas declaraciones ante las autoridades judiciales acerca de las dolencias venéreas y su tratamiento eran meramente técnicas-, y las apreciaciones que los facultativos peritos hacían de las enfermedades de contagio sexual. Así, Juan Durán, médico que atendía en su consultorio y que, además, oficiaba de perito policial de la ciudad de San Antonio de Areco, refiriéndose al chancro sifilítico de uno de los denunciantes, y paciente suyo, aclaraba que "esta afección es sumamente contagiosa, estando considerada como el más temible de los contagios venéreos". Por su parte, al interpretar los resultados de la prueba de laboratorio de Luisa, una de las mujeres denunciadas por contagio, utilizaba el exagerado calificativo de "intensamente positivo" y, al comentar el estado de salud de la otra detenida, Josefa, expresaba: "creo superfluo extenderme sobre la naturaleza de tal afección, el mal que acarrea al organismo que la padece y las consecuencias de orden social, por ser harto conocidas" 48 . Estos diagnósticos, cargados de pesimismo respecto de la salud individual de mujeres y varones, y del riesgo que corría la sociedad en su conjunto, probablemente tendían, por un lado, a justificar el inicio del proceso judicial, a partir de la denuncia por contagio venéreo; y, por otro lado, a reafirmar el lugar del perito médico como autoridad pública, responsable del bien común. No obstante, desentonaban con la posibilidad, para la época, de una cura relativamente rápida, habida cuenta del uso cada vez más expandido de la penicilina. En efecto, el gobierno peronista (1946-1955) facilitó los medios para producir dicha droga, y sus derivados farmacéuticos, en el país y a precios regulados, lo que extendió su aplicación en las patologías venéreas hacia mediados del siglo $\mathrm{XX}^{49}$.

La intención del doctor Durán, de facilitar con sus informes el proceso judicial por denuncia de contagio venéreo, podría ponerse en evidencia si contrastamos su escrito con

${ }^{47}$ DHJS, CP, C 596, F 178, 1946.

48 DHJS, CP, C 519, L 1470, 1954.

49 Pfeiffer, Ana \& Campins, Mónica, "La producción de medicamentos durante el peronismo y el conflicto con los laboratorios Massone. ¿Problema tecnológico o político?”, Ciclos, vol. XIX, n¹4, 2004, p. 123-151. 


\section{Revista Historia y Justicia}

otro del año 1946, cuando el uso de la penicilina no se había generalizado todavía en Argentina, realizado por el médico de la policía de Necochea. Para el galeno, el chancro sifilítico se curaba rápidamente (en un periodo de un año y medio a cuatro años) si el paciente era sometido al tratamiento específico: lo importante era detectar la enfermedad y tratarla ${ }^{50}$. En el fondo, más que pesimismo respecto de la posibilidad de cura, en el informe de Durán parece subyacer una carga clasista y desaprobatoria sobre la moral de varones y mujeres de los sectores populares, cuyas conductas consideraba desviadas.

Por último, los expedientes judiciales aportan indicios acerca de los procedimientos de los exámenes médicos. A Luisa, detenida en Necochea en 1954, antes de hacerle las pruebas de laboratorio "se le efectúa un raspado con ansa de platino para investigar el treponema, lo que da resultado negativo". Por su parte el médico policial informó que a la otra imputada, Josefa, le examinó los órganos genitales "no encontrando afección alguna en la vulva, vagina ni cuello uterino que pudiera ser, en este momento, motivo de contagio". De todos modos, le llamó la atención "la extrema sequedad de sus paredes vaginales que puede ser motivo de coitos laboriosos que favorecen la producción de soluciones de continuidad en las mucosas peneanas y vaginal favorables al contagio venéreo". Esta invasión del cuerpo de la mujer $-\mathrm{y}$ la interpretación acerca de sus conductas sexuales, que podrían ser evitadas con la sola prueba serológica-, se contrapone con la inexistencia de revisión médica o de análisis de laboratorio para el concubino de una de ellas. Esta práctica fue retomada como argumento de la defensa de una de las acusadas, para cuya culpabilidad solo se consideró como evidencia la propia declaración verbal del sospechado: "siendo Martínez el concubino de la Moreno, aquél también se encontraría atacado de enfermedades venéreas y en cambio manifiesta no tener enfermedad y menos de esa índole" 51.

Nuevamente lo que trasunta estas prácticas médicas es, por un lado, una concepción que asimila el foco de contagio a la mujer que ejerce la prostitución. En contraste, las féminas presumiblemente "decentes" - como aquellas que en Mar del Plata habían tenido contacto con los miembros de la base naval, pero que no fueron requeridas por la investigación policial, que acusó rápidamente a dos mujeres que mantenían relaciones sexo-comerciales-, no fueron alcanzadas por algún proceso de denuncia por contagio venéreo. En ese sentido, es posible hacer un contrapunto con los postulados que, en el debate parlamentario acerca de la imposición del certificado pre-nupcial obligatorio, excluyeron a las mujeres de ser sometidas a la prueba serológica porque, de hacerlo, arriesgaban perder su "honor" y su "decencia"52. Por otro lado, aparece en las intervenciones médicas una concepción androcéntrica de la salud, en la que el varón no solo tiene que ser protegido de los posibles

${ }^{50}$ DHJS, CP, C 596, F 178, 1946.

${ }^{51}$ DHJC, CP, C 519, F 1470, 1954.

52 Almirón, V. \& Biernat, C., "El Certificado Médico Prenupcial”, Op. Cit, p. 2-26. 
focos de contagio sino que, además, queda excluido él mismo de la posibilidad de contagiar. De allí que, en los fondos judiciales consultados, no haya aparecido ningún varón denunciado por ese motivo.

\subsection{Saberes heterogéneos, prácticas comunes}

Si bien en los casos analizados, la intermediación de los médicos en la denuncias y en el proceso judicial, y de la policía local en el armado de las causas, parecerían dejar una capacidad de agencia limitada a los denunciantes, las causas judiciales constituyen una invalorable fuente. Permiten indagar las nociones acerca de las enfermedades de transmisión sexual y su profilaxis; las prácticas de acción con las que algunos varones apelaron a la justicia; y también aquéllas con las que se defendieron las mujeres que se vieron involucradas. Se trata de saberes que, fueron asociados generalmente a los agentes estatales, o a los integrantes de la corporación médica, pero que, según dejan ver los expedientes, parecen haber sido apropiados y re-significados por los sectores populares.

Un primer aspecto a considerar es la profilaxis de las enfermedades venéreas. La lectura de los testimonios permite constatar que el uso de preservativos era, al menos, un saber popular. Así por ejemplo, en el proceso iniciado en San Antonio de Areco, en 1954, uno de los testigos, José, "hizo uso de preservativo con la gorda Josefa" y gracias a eso no fue contagiado ${ }^{53}$. En efecto, el uso de preservativos era una práctica habitual en las décadas de 1920 y 1930 en Argentina ${ }^{54}$; incluso, como lo muestran algunos expedientes judiciales, entre los sectores de menos recursos y, claramente, entre las prostitutas. Por ejemplo, René, en 1940, declaró ante la policía que utilizaba profilácticos en todos los actos sexuales a cambio de dinero. María, en la ciudad de Lobería, según atestiguaron sus clientes, utilizaba diversos medios de desinfección para evitar el contagio de sus "visitantes" 55 . No obstante, y a pesar de contar con este conocimiento, la mayor parte de los involucrados en la causa de San Antonio de Areco, como por ejemplo Eugenio, "no usaron forro sino que lo hicieron así a la 'criolla" " 56.

En este punto, más allá de que la existencia del profiláctico formara parte de un saber popular, lo que parece dirimirse es una representación, compartida por varones heterosexuales, en la que la prescindencia del uso del preservativo durante el acto sexual reforzaba su virilidad. Esa virilidad estaba asociada, por otra parte, a la responsabilidad colectiva masculina de sostener los atributos de una nacionalidad fundada en criterios androcéntricos. Realizar el coito a la "criolla" remitía no solo a la obligación de los varones

\footnotetext{
${ }^{53}$ DHJC, CP, C 519, F 1470, 1954.

${ }^{54}$ Barrancos, Dora, "Contracepcionalidad y aborto en la década de 1920: problema privado y cuestión pública", Estudios Sociales, nº 1, 1991, p. 75-87.

${ }_{55}$ DHJS, CP, C 560, F 20 y F 43, 1940.

${ }^{56}$ DHJC, CP, C 519, F 1470, 1954.
} 
en la reproducción cuantitativa de la población; también dialogaba con una imaginación en la que las relaciones carnales se anclan en un momento originario de la "invención" de la nación, la lucha de los criollos por la independencia del imperio español. Y ese momento fue rescatado por las narrativas de un nuevo nacionalismo, que fijó su enemigo en las ciudades y el cosmopolitismo ${ }^{57}$.

Aun así, al momento en que un varón tenía contacto sexual con una mujer que intercambiaba sexo por dinero, se tomaban una serie de cuidados que, en la mayoría de los casos, recaían sobre la mujer. Según lo declarado por Emilio: "la gorda Josefa no tomaba ninguna precaución en higienizarse, sino que solo se pasaba un trapo con alcohol". Pero "en lo que se refiere a la mujer que iba a la casa de Martínez, ésta después de pasar visitas con el declarante lo lavaba a cada uno, usando para ello una palangana de color blanca, como así usaba un poco de alcohol" ${ }^{58}$. Cabe aclarar que estas prevenciones no distaban mucho de las recomendaciones que las autoridades sanitarias brindaban en los consultorios venerológicos, o en las campañas de profilaxis individual, en las que insistían en el lavado de las zonas genitales previo y posterior al coito, y en el uso de pomadas antisépticas ${ }^{59}$. Respecto de la pregunta acerca de cuán extendidas eran estas prácticas, podemos subrayar que, cuando el oficial a cargo de la investigación hizo la inspección de la casa en la que los denunciantes habían mantenido relaciones sexuales con las mujeres denunciadas, secuestró como evidencia "una botella con alcohol alcanforado con poco contenido" 60 . Asumir que este hallazgo representaba por sí solo una prueba acerca de los cuidados profilácticos al momento de entablar relaciones sexuales, nos permite inferir cuán instaladas en el sentido común de la época se encontraban estas prácticas.

Si nos detenemos a preguntar cuál pudo haber sido la experiencia de los enfermos acerca del padecimiento de una dolencia venérea, las fuentes dan indicios de dos aspectos centrales. Por un lado, se trataba de una experiencia excepcional, a la que la mayoría de los afectados no estaba acostumbrada. En ese sentido, Pedro declaró que, ni bien sintió "algo anormal en el miembro", consultó al médico del pueblo ${ }^{61}$. Por su parte, Ángel manifestó que, a los pocos días de haber mantenido relaciones sexuales con una mujer, "sintió una molestia en los órganos genitales", una fuerte hinchazón y unos granos en la "cabeza del bicho", por lo que comunicó ello a su padre, quien fuera que lo llevara a revisión médica ${ }^{62}$.

\footnotetext{
${ }^{57}$ Devoto, Fernando, Nacionalismo, fascismo y tradicionalismo en la Argentina moderna: una historia, Siglo XXI, Buenos Aires, 2004.

58 DHJC, CP, C 519, F 1470, 1954.

${ }^{59}$ Biernat, C., "Médicos, especialistas, políticos y funcionarios", Op. Cit, p. 272.

${ }^{60}$ DHJC, CP, C 519, F 1470, 1954.

${ }^{61}$ DHJS, CP, C 596, F 178, 1946.

62 DHJC, CP, C 519, F 1470, 1954.
} 


\section{Revista Historia y Justicia}

Por otro lado, esta experiencia estaba acompañada de un sentimiento de vergüenza que los conducía a dilatar, según lo relatado por Eugenio y Ricardo, la consulta al médico ${ }^{63}$. Resulta interesante destacar la permanencia del estigma vergonzante de las enfermedades de transmisión sexual a mediados del siglo XX, a pesar de haber mediado campañas públicas, en las que se intentó transformar la lectura del carácter individual e ignominioso de estas dolencias en una interpretación diferente, en la que la responsabilidad colectiva acerca de la salud de la población, presente y futura, asumió un primer plano. En este sentido, surge una pregunta: la búsqueda de una condena judicial para la mujer que había contagiado, ¿no podría ser pensada como una compensación para el enfermo, en la medida que transfería el propio estigma a un tercero? Retomando la idea del proceso judicial como un ritual, la vergüenza del varón advenido en víctima, le quitaría el estigma y lo colocaría como el único perjudicado. Mientras que, finalizado el proceso (sea su resultado punitivo o curativo, a través de la internación forzosa), el estigma se le transferiría a otra, que ahora sería catalogada como "prostituta".

Desde la óptica de las mujeres que eran denunciadas por contagio, su enfermedad no siempre era asumida como transmisible. Así por ejemplo, Josefa, declaró que no estaba enferma porque "su mal lo tiene en la sangre y por herencia pero nunca con ello puede ocasionar un contagio". Según ella, el padecimiento de sífilis congénita podía constituir un estigma heredado de su madre, que había sido internada tres veces en un establecimiento de enfermos mentales, y se suicidó a los 20 años, pero nunca como una enfermedad que pudiese transmitir a otras personas y, con ello, poner en riesgo la salud ajena ${ }^{64}$. En su declaración pareciera subyacer una noción de la enfermedad como algo transmisible hereditariamente y por línea femenina; pero además, como una experiencia individual, muy alejada de la interpretación médica que trataba un asunto de responsabilidad colectiva.

De todos modos, esta declaración, además de reportar una experiencia subjetiva de la enfermedad, vivida como estigma social por su transmisión intergeneracional, también puede ser interpretada como un conocimiento que poseían muchas de las mujeres denunciadas por contagio venéreo. Ese conocimiento resultaba central para ellas a la hora de ser absueltas: la mayoría de ellas alegaba desconocer que padecían una dolencia de transmisión sexual, amparándose en el artículo 18 de la ley $\mathrm{n}^{\circ} 12.331$, que ponía como condición, para la determinación de la pena, el saberse afectado por la enfermedad. Por ejemplo, Catalina, acusada por el joven pescador de Necochea de haberlo contagiado de blenorragia, declaró en el proceso de instrucción que ella nunca había tenido "ni lesiones internas ni externas", y que

${ }^{63}$ DHJC, CP, C 519, F 1470, 1954.

${ }^{64}$ DHJC, CP, C 519, F 1470, 1954. 
se enteró, por el examen del médico policial, de que estaba enferma. Según su declaración, de haberlo sabido, ella no hubiese propagado la dolencia. Por otro lado -probablemente en orden de no comprometer ni acusar a nadie-, aseguró no poder precisar una fecha, ni el nombre de la persona que le hubiese contagiado la enfermedad. Tampoco quiso involucrar a su pareja, con quien dijo no haber tenido "acceso carnal" durante el mes anterior. No obstante, el marido, Francisco, también fue convocado ante la justicia, y se ofreció a hacerse un examen para probar que no poseía enfermedad venérea y que su mujer no lo había contagiado. El informe médico aseguraba que no poseía síntomas de padecer o haber padecido la enfermedad ${ }^{65}$.

Finalmente, Catalina fue detenida, se le inició un proceso judicial penal en la ciudad de Dolores, y fue sobreseída provisionalmente por no fue declarada responsable del delito (la evidencia más fuerte era que, mientras ella poseía sífilis, el denunciante la acusaba de haberlo contagiado de blenorragia); pero sí se le ordenó que comenzara un tratamiento, de lo contrario se procedería a su hospitalización forzosa ${ }^{66}$.

La otra acusada, Carolina, estuvo prófuga por unos meses, y cuando finalmente fue detenida, explicó que se había ido a Mar del Plata porque se había enterado de que la buscaba la policía. En esa ciudad se hizo atender por un médico, quien, tras hacerle exámenes de orina y de sangre, le informó que estaba enferma, pero no le dijo de qué. Una vez apresada, declaró ante el juez que no sabía que padecía enfermedad alguna y que tampoco tuvo sexo con alguien que ella supiese estaba contagiado. Finalmente fue sobreseída, y el juez pidió que se informase a las autoridades sanitarias que padecía sífilis ${ }^{67}$.

En los casos analizados, la táctica de declarar no saberse enferma ofició de argumento central para ser sobreseídas, junto con aquella de no involucrar a otra persona que posteriormente se pudiera denunciar como foco de contagio. Probablemente se trataba de una recomendación de los abogados defensores, o de un saber que circulaba previamente en los círculos sociales en los que estas mujeres se movían. Los fiscales y los jueces coincidieron en aceptar este argumento, y terminaron absolviendo a las acusadas, bajo la condición de que siguieran un tratamiento médico para sus dolencias. Claro está que los casos considerados solo sirven para analizar los saberes con los que las mujeres denunciadas contaban para evitar ser condenadas, y que en ningún caso puede extraerse de ellos conclusiones generales. En efecto, como afirmamos en el primer apartado, hubo mujeres que finalmente cumplieron con una condena por delito de contagio venéreo.

${ }^{65}$ DHJS, CP, C 596, F 178, 1946.

${ }_{66}^{6}$ DHJS, CP, C 596, F 178, 1946.

${ }^{67}$ DHJS, CP, C 596, F 178, 1946. 


\section{A modo de conclusión}

A mediados de la década de 1930, una nueva agenda sanitaria en torno a la profilaxis de las enfermedades de transmisión sexual logró imponerse en Argentina, a través de la sanción y reglamentación de la ley $\mathrm{n}^{\circ} 12.331$. En la normativa se conjugaron disposiciones de orden preventivo, curativo y de organización administrativa. En este artículo nos hemos focalizado en uno de los aspectos de la profilaxis: la denuncia judicial por contagio venéreo. El análisis de un tema aparentemente marginal de la ley nos permite avanzar en dos tipos de conclusiones.

Por un lado, el actuar del Poder Judicial: lejos de constituirse en un aliado de las reparticiones sanitarias nacional y provinciales en el control de los padecimientos de transmisión sexual, su lógica de funcionamiento y sus criterios de legitimación obstruyeron, en la mayoría de los casos, la posibilidad de penalizar el contagio venéreo, y de controlar, de ese modo, los focos de infección. Las críticas desde el campo médico, y desde los funcionarios sanitarios, dirigidas a esta limitación impuesta por los procedimientos judiciales, llevó a un intenso debate académico y político, que coaguló, en 1946, en un decreto reglamentario de la ley, esta vez con un sesgo mucho más punitivo. No obstante, y a pesar de un aumento de la judicialización de las denuncias por contagio sexual, la mayor parte de las acusadas fueron absueltas.

El segundo aspecto analizado en este trabajo, poco abordado por la historiografía sobre la salud y la enfermedad, permitió mejorar nuestros saberes sobre el actuar de los contagiados. Se perfila un rol activo de los enfermos de dolencias de transmisión sexual, a través de la reconstrucción de las nociones y las prácticas de acción con las que los enfermos apelaron a la justicia. En ese sentido, varones y mujeres se apropiaron de los recursos que la ley y los procedimientos judiciales les proveían, para asignar un sentido y una lógica distinta a sus enfermedades, y dirimir otras batallas. En ese proceso, los denunciantes negociaron con los agentes judiciales su status de masculinidad y virilidad, basados en conceptos androcéntricos con los que entendían las ideas de "salud" y "justicia", para argumentar la necesidad de acción estatal frente a conflictos individuales que excedían al contagio de enfermedades sexuales, tales como los celos, la vergüenza o el temor a la corrección paterna. Por su parte, las mujeres denunciadas, en su mayoría ofertantes de sexo por dinero, utilizaron los recursos que la misma normativa les proveía (no ser conscientes de poseer una enfermedad transmisible) para declararse inocentes, pero refrendaron el carácter patriarcal de la norma en la medida que defendieron a sus cónyuges y a sus clientes con el silencio, o con la negación de haber mantenido contacto carnal con ellos, y con la incorporación, en ellas mismas, de la responsabilidad de preservar la salud de los varones. 
En suma, las fuentes judiciales nos permiten indagar en aspectos experienciales de las enfermedades, entendidas como un hecho individual y, a la vez, social. En la confluencia entre el lenguaje normalizador de la ley y de la justicia, con las prácticas de los actores, aparecen nuevas significaciones y apropiaciones que nos hablan no solo de cuerpos dóciles y disciplinados, sino también, de construcciones de sentidos mucho menos estables, que surgen de negociaciones y de relativos grados de autonomía.

\section{Fuentes}

\section{Inéditas}

Departamento Histórico Judicial Centro de la Provincia de Buenos Aires, Mercedes, Causas Penales, Carpeta 519, Folio 1470, 1954.

Departamento Histórico Judicial Sur de la Provincia de Buenos Aires, Dolores, Causas Penales, Carpetas -560, Folio 20 y Folio 43, 1940. -596, Folio 178, Año 1946. -733, Folio 9, Año 1952.

Archivo del Servicio Penitenciario de la provincia de Buenos Aires, Cárcel de Olmos, 1936-1968.

\section{Publicadas}

"II Conferencia Panamericana de directores nacionales de sanidad", Boletín de la Oficina Sanitaria Panamericana, vol. 10, n⿳6, 1931.

"VII Conferencia Sanitaria Panamericana”, Boletín de la Oficina Sanitaria Panamericana, vol. 6, n¹2, 1927. Anales de la Legislación Argentina, 1920-1940, Buenos Aires, La Ley, 1953.

Ambrosino, Nicolás \& Berenguer, Alfredo, "Contagio sifilítico familiar. Responsabilidad y previsión”, Revista de la Asociación Argentina de Venerología y Profilaxis Social, vol. 1, n², 1937, p. 145-150.

Baliña, Pedro, "Libreta de salud obligatoria y lucha antivenérea", Revista Argentina de Dermatosifilología, 1937, n²1 p. 611-622.

Carnelli, Luis, Anales de Legislación Argentina 1920-1940, La Ley, Buenos Aires, 1953.

Fidanza, Eduardo, "Para que la ley de profilaxis de las enfermedades venéreas n¹2.331 y su reglamentación resulten benéficas, se hace indispensable su modificación”, Revista Argentina de Dermatosifilología, vol. XII, n4, 1938, p. 608-620.

Landaburu (h), Leónidas \& Aftalión, Eduardo, “Aspectos civiles, penales y administrativos de la ley 12.331 de profilaxis antivenérea”, Revista Argentina de Dermatosifilología, vol. 12, n4, 1942, p. 763-774.

Rebaudi, Leónidas \& Paniza, Ignacio, "Comentario sobre la denuncia obligatoria de los enfermos venéreos", Revista de la Asociación Argentina de Venerología y Profilaxis Social, vol. X, n¹8, 1946, p. 109-111. 


\section{Revista Historia y Justicia}

ISSN 0719-4153 revista.historiayjusticia.org

N¹0 - Santiago de Chile, abril 2018, p. 104-129

"Reglamentó el P. E. la ley de Profilaxis Social", Revista de la Asociación Argentina de Venerología y Profilaxis Social, vol. X, n¹8, 1946, p. 47-56.

Rojas, Nerio, "Delito de contagio venéreo. Dolo Eventual”, Archivos de Medicina Legal, vol. IV, n4, 1934, p. 163-174.

Tey, Aftalión \& Garzón, Roberto \& Brandan, Gerardo, "Informe presentado por la subcomisión del Círculo Médico de Córdoba (a propósito de la ley n¹2.331 de profilaxis de las enfermedades venéreas y su reglamentación)", Revista Argentina de Dermatosifilología, vol. XII, 1938, p. 159-182.

VV AA, "Legislación Sanitaria”, Boletín Sanitario del Departamento Nacional de Higiene, vol. 1, n¹, 1937, p. 402-406.

\section{Bibliografía}

Almirón, Valeria \& Biernat, Carolina, "El Certificado Médico Prenupcial como política social", De prácticas y discursos, vol. 4, n², 2015, p. 2-26.

Armus, Diego, "Cuando los enfermos hacen huelga. Argentina, 1900-1940”, Estudios Sociales, Santa Fe, vol. XI, n²0, 2001, p. 32-45.

Barclay, Katie, "Singing, Performance, and Lower-Class Masculinity in the Dublín Magistrates'Court, 1820-1850", Journal of Social History, vol. 47, n³, 2014, p. 746-768.

Barona, Josep Lluis \& Bernabeu-Mestre, Josep, La salud y el Estado. El movimiento sanitario internacionaly la salud española (1851-1945), Universidad de Valencia, Valencia, 2008.

Barrancos, Dora, "Contracepcionalidad y aborto en la década de 1920: problema privado y cuestión pública”, Estudios Sociales, n¹, 1991, p. $75-87$.

Biernat, Carolina, "Médicos, especialistas, políticos y funcionarios en la organización centralizada de la profilaxis de las enfermedades venéreas en la Argentina (1930-1954)", Anuario de Estudios Americanos, vol. 64, nº , 2007, p. 257-288.

Biernat, Carolina, "Debates poblacionistas en la matriz de la política social argentina de entreguerras", Anuario del Centro de Estudios
Históricos Profesor Carlos Segreti, vol. 11, n ${ }^{\circ 11}$, 2011, p. 189-208.

Biernat, Carolina, "Entre el abolicionismo y la reglamentación: prostitución y salud pública en Argentina (1930-1955)", Cuadernos del Sur, vol. $40, n^{\circ} 3,2013$, p. 29-48.

Biernat, Carolina, "La eugenesia como matriz ideológica de la política sanitaria (1900-1955)" en Biernat, Carolina \& Cerdá, Juan Manuel \& Ramacciotti Karina, La salud pública y la enfermería en la Argentina, Editorial de la Universidad Nacional de Quilmes, Bernal, 2015, p. 169-204.

Biernat, Carolina \& Simonetto, Patricio, "Producción, distribución y publicidad de medicamentos en la política de profilaxis venérea argentina de los años treinta" en Carvajal, Yuri \& Correa, María José, Historia de los medicamentos. Apropiaciones e invenciones en Chile, Argentina y Perú, Ocho Libros Editores, Santiago, 2016, p. 158-179.

Biernat, Carolina \& Simonetto, Patricio, "Provisión pública y oferta privada de medicamentos contra las enfermedades venéreas. Argentina 1930-1945”, Revista de Ciencias de la Salud, vol. 15, n², 2017, p. 54-78.

Farge, Arlette, La atracción del archivo, Edicions Alfons el Magnanim, Valencia, 1991.

Fleck, Ludwig, La génesis y el desarrollo de un hecho cientifico, Alianza, Madrid, 1986. 
Grammático, Karin, “Obreras, prostitutas y mal venéreo. Un Estado en busca de la profilaxis" en Gil Lozano, Fernanda et al (dir.), Historia de las mujeres en la Argentina del siglo XX, tomo 2, Siglo XX, Taurus, Buenos Aires, 2000, p. 86-104.

Guy, Donna, El sexo peligroso: la prostitución legal en Buenos Aires, 1895-1955, Sudamericana, Buenos Aires, 1994.

Maynes, Mary \& Pierce, Jennifer \& Laslett, Bárbara, Telling stories: The use of personal narratives in the social sciences and history, Cornell University Press, New York, 2012.

Miranda, Marisa, "Matrimonio y procreación en la ortodoxia eugénica argentina", Sociobistórica, vol. $17, \mathrm{n}^{\circ} 1,2005$, p. 151-178.

Miranda, Marisa, "Sobre las asalariadas del amor: prostitución y norma (Argentina y España, findu-siècle)", Trabajos y comunicaciones, vol. $42, \mathrm{n}^{\circ} 1$, 2015, p. 1-13.

Melanesio, Natalia, “Redfining Men's Sexuality, Resignifying Male Bodies: The Argentine Law of
Anti-Venereal Prophylaxis, 1936”, Gender \& History, vol. 17, n², 2005, p. 463-491.

Mujica, María Luisa, "Males vergonzantes y prostitución reglamentada. Rosario, Argentina (1874-1932)", Asclepio. Revista de Historia de la Medicina y de la Ciencia, vol. 68, n², 2016, p. 35-49.

Pfeiffer, Ana \& Campins, Mónica, “La producción de medicamentos durante el peronismo y el conflicto con los laboratorios Massone. ¿Problema tecnológico o político?”, Ciclos, vol. XIX, n¹4, 2004, p. 123-151.

Putnam, Laura, The Company They Kept: Migrants and the Politics of Gender in Caribbean Costa Rica, 1870-1960, University of North Carolina Press, Chapel Hill, 2002.

Queirolo, Graciela, "Género y sexualidad en tiempos de males venéreos (Buenos Aires, 19201940)", Nomadías, vol. 17, n¹, 2013, p. 67-88.

Riva, Betina, El perito médico en los delitos sexuales, Tesis Doctoral. Facultad de Humanidades y Ciencias de la Educación de la Universidad de La Plata, Argentina, 2011. 